\title{
Model Pertanian Terpadu Tanaman Hortikultura dan Ternak Sapi untuk Meningkatkan Pendapatan Petani
}

\section{Integrated Farming System for Horticulture and Beef Cattle to Improve Farmer Income}

\author{
L. Siswati dan R. Nizar \\ Faculty of Agriculture, University of Lancang Kuning \\ Jl. Yos Sudarso Km 8 Rumbai, Pekanbaru \\ E-mail: latifasiswati@yahoo.com \\ (Diterima: 12 Desember 2011, Disetujui: 28 Mei 2012)
}

\begin{abstract}
Research was conducted to identify the diversity of technologies in an integrated farming system for horticulture and beef cattle. Furthermore, it observed the improving of farmer income that used this model. There were primary and secondary data with the survey method for farmers in Pekanbaru. The result showed the integrated farming system kept up to 21 heads of beef cattle and 4,22 ha of holticultures. Every farmer had around 0,3 ha farmland and approximately 4 to 5 heads of beef cattle. Finally, the integrated farming system increased the farmer income about $R p 9.731 .147$ per cultivating period of holticultures and about $R$ p. 9.345.328 per year of keeping the beef cattles.
\end{abstract}

Keywords: integrated farming system, horticulture, beef cattle, farmer income

\section{PENDAHULUAN}

Tanaman hortikultura merupakan tanaman yang sangat dibutuhkan oleh manusia untuk memenuhi kebutuahan vitamin dan mineral. Sayuran hijau bermanfaat sebagai sumber vitamin dan mineral yang penting bagi pemenuhan gizi masyarakat. Dengan bertambahnya penduduk, meningkatnya pendapatan dan pendidikan akan mempengaruhi kesadaran masyarakat terhadap pentingnya nilai gizi dan kesehatan. Konsumsi sayur sayuran dan buahbuahan oleh penduduk di Indonesia sampai dengan tahun 2007 baru sebesar $95 \mathrm{kkal} /$ kapita/hari atau 79 persen dari anjuran kebutuhan minimum sebesar 120 kkal/ kapita/hari (Aswatini, dkk. 2008).

Produksi sayuran di Pekanbaru masih diusahakan dengan pola usahatani kecil dengan memanfaatkan lahan tidur. Sesuai dengan anjuran pemerintah kota Pekanbaru melalui Badan Ketahanan Pangan, dengan memanfaatkan lahan ini untuk usahatani sayur-sayuran masyarakat bisa mandiri untuk pemenuhan kebutuhan masyarakat terhadap sayur-sayuran dan juga merupakan sumber pendapatan bagi petani yang mengusahakannya. Lahan tidur yang digunakan untuk usahatani sayur-sayuran di Kota Pekanbaru banyak terdapat di Kecamatan Tampan, Kecamatan Marpoyan Damai, Kecamatan Rumbai.

Upaya yang dapat dilakukan agar hasil tanaman hortikultura dapat meningkat dan kualitasnya menjadi lebih baik, selain penggunaan varietas unggul, pengendalian hama dan penyakit, pengaturan jarak tanam yang tepat, ketepatan waktu panen dan penggunaan pupuk yang tepat juga merupakan factor yang perlu diperhatikan , baik jenis pupuk,takaran ,cara dan bahan bakunya yaitu pupuk organic dan anorganik. Penggunaan pupuk anorganik yang selama ini digunakan oleh petani apabila digunakan terus menerus dapat menyebabkan dampak negativ terhadap lingkungan,antara lain tanah menjadi padat akibat efek rekat (glueing effect) terutama pada pupk ammonium, bereaksi masam dan bila tercuci samapai ke air tanah bila air dikomsumsi dapat menimbulkan penyakit. Oleh karena itu penggnaan pupuk organik perlu ditingkatkan ketersediaannya untuk 
keseimbangan hara tanah, walaupun persentase kandungan unsur hara dalam pupuk anorganik relativ lebih tinggi dibanding pupuk organik tetap digunakan karena fungsinya belum tergantikan oleh pupuk anorganik (Novizan, 2002).

Kotoran ternak sapi merupakan sumber pupuk organik bagi tanaman hortikultura dan tidak memerlukan biaya besar untuk di gunakan. Hutabarat (2002) kotoran sapi dapat mengurangi biaya pengadaan pupuk yang sekaligus dapat mengurangi biaya produksi di samping menjaga kelestarian bahan organik, sehingga dapat meningkatkan pendapatan.

Penelitian ini bertujuan untuk menemukan model pertanian terpadu hortikultura dan ternak sapi, dari limbah tanaman hortikultura di jadikan makanan ternak sapi, kotoran ternak /feses dijadikan pupuk tanaman .Untuk meningkatkan pendapatan petani.

\section{METODE}

\section{Lokasi dan waktu Penelitian}

Lokasi penelitian di kota Pekanbaru. Penelitian dilakukan secara survey ,teknik pengambilan sampel Responden dipilih secara purposive sampling dimana petani yang melakukan pertanian terpadu tanaman hortikultura dan ternak sapi, selanjutnya untuk pemilihan Kecamatan yang petaninya melakukan pertanian terpadu tanaman hortikultura dan ternak sapi, yaitu Kecamatan Marpoyan Damai, Kecamatan Bukuit Raya, Kecamtan Tenayan Raya, Kecamatan Rumbai.

\section{Tahapan dan Sasaran Penelitian}

Penelitian ini untuk menemukan model pertanian terpadu tanaman hortikultura dan ternak. Penelitian ini dilaksanakan di kota Pekanbaru. Pada tahun pertama selama delapan bulan.

Metode yang digunakan dalam penelitian ini adalah metode survey. Unit analisis dalam penelitian ini adalah keluarga petani peternak yang melakukan usaha tanaman hortikultura. Sampel bersifat disengaja yang dipilih atas dasar pertimbangan tertentu yaitu: kelurahan yang melakukan pertanian terpadu tanaman hortikultura dan ternak sapi. Dari kelurahan yang terpilih diambil sampel keluarga secara purposive sampling dengan kriteria keluarga yang melakukan pertanian terpadu tanaman hortikultura dan ternak sapi. Diambil responden sebanyak 70 kepala keluarga. Penelitian dilaksanakan di kota Pekanbaru dengan memilih Kecamatan yang petaninya melakukan pertanian terpadu.

Lokasi penelitian yang terpilih adalah 4 Kecamatan yaitu:

1.Kecamatan Tenayan Raya

2.Kecamatan Marpoyan Damai

3.Kecamatan Bukit Raya

4.Kecamatan Rumbai

Data yang di kumpulkan dalam penelitian ini terdiri dari data primer dan data sekunder. Data primer diperoleh langsung dari keluarga petani peternak yang terpilih sebagai sampel dan dikumpul melalui wawancara dan pengisian daftar pertanyaan. Data sekunder diperoleh dari berbagai instansi terkait.

Adapun petani sebagai responden dalam penelitian ini dengan kriteria sebagai berikut : Petani mempunyai salah satu macam pola pertanian terpadu tanaman hortikultura dan ternak; a. tanaman sayuran dan ternak sapi.b. tanaman buah-buahan dan ternak sapi

\section{Analisis data}

Analisis data untuk optimasi digunakan metode linear programming. Dimana metode linear programming mempunyai tiga komponen kuantitatif yaitu: fungsi tujuan, aktivitas/proses mencapai tujuan sumber daya terbatas.

Fungsi tujuan merupakan fungsi yang menggambarkan tujuan yang berkaitan dengan pengaturan secara optimal sumberdaya untuk memperoleh keuntungan maksimal atau biaya minimal, secara umum fungsi tujuan untuk mencapai keuntungan maksimal ditulis sebagai berikut:

$$
\begin{aligned}
& \mathrm{Z}=\mathrm{C}_{1} \mathrm{X}_{1}+\mathrm{C}_{2} \mathrm{X}_{2}+\ldots .+\mathrm{C}_{\mathrm{i}} \mathrm{X}_{\mathrm{i}} \\
& \text { Keterangan : } \\
& \mathrm{Z}=\text { Jumlah keuntungan maksimal } \\
& \mathrm{C}_{\mathrm{i}}=\text { Keuntungan persatuan output cabang } \\
& \quad \text { usaha ke }-\mathrm{i} \\
& \mathrm{X}_{\mathrm{i}}=\text { Jumlah output dari cabang usaha ke I }
\end{aligned}
$$


$\mathrm{i}=1,2,3, \ldots ., \mathrm{n}$

Untuk memproduksi tanaman dan ternak maka diperlukan sumberdaya. Sumberdaya yang dimiliki petani adalah terbatasnya jumlah ,maka menjadi persoalan adalah bagaimana memanfaatkan sumberdaya yang dimiliki petani tersebut dapat ditulis sebagai berikut :

$\mathrm{A}_{11} \mathrm{X}_{11}+\mathrm{A}_{12} \mathrm{X}_{12}+\ldots+\mathrm{A}_{1 \mathrm{~K}} \mathrm{X}_{1 \mathrm{~K}}<\mathrm{h}_{1}$

$\mathrm{A}_{21} \mathrm{X}_{1}+\mathrm{A}_{22} \mathrm{X}_{2}+\ldots+\mathrm{A}_{2 \mathrm{~K}} \mathrm{X}_{\mathrm{K}}<\mathrm{h}_{2}$

$\begin{array}{lllll}\mathrm{A}_{21} \mathrm{X} & +\ldots & \ldots \ldots & \ldots & \ldots \ldots\end{array}$

$\ddot{A}_{\mathrm{Ji}} \mathrm{X}_{1}+\mathrm{A}_{\mathrm{j} 2} \mathrm{X}_{2}+\ldots .+{ }_{\mathrm{A}} \cdot \ldots \mathrm{A}_{\mathrm{jK}}<\mathrm{h}_{\mathrm{j}}$

Keterangan :

$\mathrm{h}$ = sumberdaya yang terbatas yang dimiliki petani

$\mathrm{j}$ = sumberdaya yang pergunakan

$\mathrm{k}=$ jumlah aktivitas.

\section{Aktivitas -aktivitas:}

1. Pola tanam, aktivitas produksi tanaman berdasarkan tanaman yang banyak dijumpai dan berpotensi tinggi serta telah rekomendasikan oleh dinas pertanian setempat.

2. Ternak ruminansia, aktivitas pemeliharaan ternak pemakan rumput seperti sapi. Hasil penjualan produksi ternak dihitung dalam satu tahun.

3. Produksi Pakan Hijauan, aktivitas dalam produksi rumput unggul lahan sendiri.

4. Pembelian Input Produksi. Aktivitas ini meliputi pembelian input pupuk anorganik,pupuk kandang,rumput,sewa tenaga kerja.Apabila tenaga kerja keluarga dan rumput tidak mampu untuk menyediakan jumlah yang dibutuhkan maka tenaga kerja dan rumput harus di datangkan dari luar.

5. Penyewaan Tenaga Kerja Keluarga. Aktivitas yang memanfaatkan kelebihan tenaga kerja keluarga sesuai dengan tingkat upah tenaga kerja bila menyewa. Penyewaan tenaga kerja ini merupakan pendapatan usha tani.

\section{Sumberdaya :}

1. Lahan usahatani ,rata-rata luas lahan yang dimiliki petani untuk tanaman pangan, alternative pola tanam yang diusahakan pada lahan tersebut seperti ; kacang, cabe,singkong dsb. Untuk analisis kendala lahan dinyatakan dalam satuan luas yaitu hektar.

2. Tenaga Kerja Keluarga, merupakan sumber utama dalam melaksanakan aktivitas usahatani, aktivitasnya meliputi pengelilaan lahan sampai panen juga memelihara ternak. Persediaan tenaga kerja keluarga pria dan wanita selama satu bulan diasumsikan 25 hari kerja. Tenaga kerja anak tidak diikut sertakan dalam penyediaan tenaga kerja.Unit satuan analisis dipergunakan hari kerja untuk masingmasing jenis tenaga kerja.

3. Pupuk anorganik ,satuan fisik untuk kendala pupuk anorganik yang dipergunakan adalah kilogram, seperti ; urea, KCL, TSP.

4. Pupuk kandang ,kendala pupuk kandang yang dipergunakan dalam usahatani, adalah pupuk kandang berasal dari ternak ruminansia, satuan fisik untuk kendala pupuk kandang adalah kilogram.

5. Bibit tanaman, kendala input bibit tanaman yang digunakan dalam ushatani kacang, singkong, cabe, dan sebagainya. Satuan fisik analisis untuk tanaman adalah kilogram.

6. Ternak ruminansia, jumlah ternak ruminansia dalam ekor yang dimiliki seperti sapi.

7. Biaya lain, satuan kendala biaya lain adalah; nilai uang dalam ribuan rupiah. Angka yang dipergunakan adalah angka yang diperolah dari rata-rata biaya lainnya yang dikeluarkan oleh petani selama musim tanam, angka tersebut adalah angka maksimum dikeluarkan oleh petani. Biaya lain meliputi biaya obat-obatan, untuk tanaman dan ternak.

8. Batas maksimum dan minimum penyewaan tenaga kerja keluarga. Kendala ini merupakan batas maksimum dan minimum yang dapat dilakukan dari penyewaan tenaga kerja, satuan fisik analisis adalah hari kerja.

\section{Sistematika penerapan hasil}

1. Setiap petani yang memiliki ternak sapi dan tanaman hortikultura, yang belum menanam rumput unggul,disela sayuran 
tersebut ditanam rumput unggul dan tanaman pangan seperti jagung ,kacang kedelai,singkong.

2. Setelah ditaman diadakan penyuluhan tentang cara pemeliharaan,penanenan dan melakukan perhitungan analisa usahatani .

3. Pengambilan data hasil penelitian secara berkala, setelah memperoleh data optimal pola usahatani ,tamanan hortikultura dan ternak yang memberikan pendapatan maksimal kepada petani dijadikan acuan.

4. Setelah satu kelompok berhasil akan digulirkan ke kelompok lainnya sehingga masyarakat yang berada di kota Pekanbaru yang tinggal di pinggiran kota yang masih ada lahan kosong untuk dijadikan mata pencaharian mereka.

\section{HASIL DAN PEMBAHASAN}

\section{Produktivitas tanaman Hortikultura yang Mendukung Pengembangan Ternak Sapi}

Masalah utama dalam pengembangan tanaman hortikultura adalah rendahnya produktivitas dan mutu hasil sayuran rakyat. Hal tersebut disebabkan oleh sistem pengelolaan kebun yang tidak efisien, karena jumlah tenaga kerja yang digunakan untuk menyiangi tanaman gulma terlalu banyak, dan pupuk yang digunakan untuk tanaman menggunakan pupuk buatan yang biayanya sangat mahal, namun di kota Pekanbaru sisa tanaman sudah dijadikan pupuk organic, kotoran sapi dan kambing serta urin telah dijadikan pupuk tanaman.

Peningkatan produktivitas tanaman hortikultura dapat dilakukan dengan efisiensi dalam memanfaatkan lahan maupun tenaga kerja, serta menekan biaya pemupukan. Efisiensi pemupukan dapat dilakukan apabila jumlah pemberian pupuk kimia dapat dikurangi namun kesuburan lahan harus tetap terjaga. Hal ini dapat dilakukan antara lain dengan penyediaan bahan organik atau kompos yang dapat diperoleh dengan cara mudah dan murah dari kotoran sapi. Hal ini sesuai dengan pendapat Corley (2003) yang menyatakan bahwa ternak sapi berperan sebagai mesin pengolah limbah atau pabrik penghasil bahan organik, dimana ternak sapi berpotensi menghasilkan kompos yang sangat dibutuhkan untuk pemeliharaan kesuburan tanah.

Ketergantungan usaha tani terhadap pupuk anorganik (komersial) yang semakin mahal dan langka dapat dikurangi karena pupuk organik (kompos) dapat digunakan sebagai pupuk tambahan dan potensial meningkatkan efisiensi biaya pemeliharaan tanaman holtikultura. Adanya kotoran sapi dapat mengurangi biaya pengadaan pupuk yang sekaligus dapat mengurangi biaya produksi di samping menjaga kelestarian bahan organik tanah. Setiap ekor sapi dewasa atau satu satuan ternak (1 ST) menghasilkan feses $8-10 \mathrm{~kg} / \mathrm{hari}$ (basah) yang dapat diolah sebagai pupuk organik sekitar $2-3 \mathrm{~kg} / \mathrm{hari}$, sehingga dalam satu tahun diperkirakan mampu menghasilkan hampir 0,5 ton pupuk organik. Hasil analisis kandungan unsur hara pupuk kompos $(\mathrm{N}=0,89 \%, \mathrm{P}=0,06 \%$ dan $\mathrm{K}$ $=0,51 \%)$ maka setiap ton kompos setara dengan 19,2 kg Urea, 10,87 kg TSP dan 92,52 MOP.

Dari hasil pengamatan di lapangan sebagian besar petani telah menggunakan kotoran ternak sebagai pupuk sayur yaitu sebanyak 63 orang responden (90\%), namun sangat sedikit responden yang mengolahnya menjadi kompos yaitu 5 orang responden $(7,14 \%)$. Penggunaan kotoran ternak sebagai pupuk telah disadari oleh petani dapat meningkakan kesuburan tanah dan meningkatkan efisiensi pemupukan.

Ternak mempunyai posisi yang strategis dalam system pertanian terpadu (Hasnudi dan Saleh,2004), yakni melalui ternak selain diperoleh produksi utama berupa daging, juga akan diperoleh limbah berupa kotoran padat dan cair untuk pupuk organic dan biogas. Pupuk kandang selanjutnya digunakan untuk budidaya pertanian organik dan penanaman rumput-rumputan sebagai pakan ternak, sehingga terjadi siklus hara secara berkelanjutan. Di kota Pekanbaru sudah ada petani yang menjadikan kotoran sapi untuk biogas sehingga untuk memasak dan kebutuhan listrik rumahtangga sudah ter- 
panuhi, sehingga dapat mengurangi pengeluaran rumahtangga.

\section{Potensi Hasil Samping dan Limbah Tanaman Hortikultura dalam Pemenuhan Kebutuhan Pakan Ternak}

Pengembangan ternak sapi yang dipelihara dengan tanaman hortikultura tidak membutuhkan sumberdaya lahan baru dan sumberdaya alam yang ada, limbah tanaman hortikultura dapat di jadikan pakan ternak yang setiap di panen sehingga kebutuhan pakan ternak setiap hari dapat tersedia. Petani dapat memanfaatkan lahan kosong lebih optimal guna meningkatkan manfaat ekonomi. Sumberdaya input usaha ternak melimpah seperti hijauan antar tanaman (dari hasil pengamatan yaitu berupa rumput dan legume) dapat langsung dimanfaatkan sebagai pakan ternak tanpa mengganggu produktivitas sedangkan potensi limbah tanaman hortikultura dengan teknologi sederhana dapat dimanfaatkan sebagai bahan campuran hijauan pakan ternak sapi. Pematang tanaman hortikultura kosong masih bisa dimanfaatkan untuk budidaya rumput unggul.

\section{Tingkat Pendapatan dan Kesejahteraan Petani}

Tingkat pendapatan petani di kota Pekanbaru cukup tinggi dibandingkan dengan Upah Minimum Regional (UMR) daerah Riau, yang hanya sebesar Rp. 1.250.000,-. Hal ini banyak dipengaruhi oleh permintaan hortikultura dan daging untuk masyarakat kota Pekanbaru setiap hari bertambah sehingga dengan bayaknya penjualan maka pendapatan petani meningkat dan lebih tinggi sayuran yang ditanam di Pekanbaru setelah panen langsung di ambil oleh pedagang dan langsung di jual ke pasar sehingga sayuran dan buah-buahan masih segar sampai di tangan konsumen. Pendapatan petani dari hortikultura perperiode tanam $\operatorname{Rp} 9.731 .147$,dari usaha ternak $\mathrm{Rp}$ 9.345.328,- per tahun.sedangkan hasil penelitian Nizar,R dan Niken , N (2011) pendapatan petani sayuran di kelurahan Sidomulyo Rp 5.928.400,-per periode tanam Tanaman hortikultura harga tidak stabil tergantung musim dan kebutuhan masyarakat. Sampai saat ini usaha ternak sapi yang dilakukan petani responden sebagai usaha sambilan dan belum menjadi usaha pokok, dimana rata-rata kepemilikan ternak sapi masih rendah yaitu 4 -5 ekor. Kalau ternak harga jual akan meningkat jika ada hari besar agama seperti hari raya idil fitri dan idil adha,karena permintaan daging meningkat.

Hutabarat (2002) menyatakan bahwa adanya kotoran sapi dapat mengurangi biaya pengadaan pupuk yang sekaligus dapat mengurangi biaya produksi di samping menjaga kelestarian bahan organik tanah khususnya wilayah perkebunan berlereng. Sedangkan Ginting (1991) melaporkan bahwa ternak dapat berperan sebagai industri biologis sekaligus mampu meningkatkan produksi daging dan penyedia kompos.

Pada dekade tahun 1990 -an telah diintensifkan integrasi tanaman padi dan ternak sapi. Dalam hal ini dioptimalkan pemanfaatan pupuk organik berasal dari kotoran sapi biasa mencapai $40 \%$ dari pendapatan (Dwiyanto ,dkk.2001). Bertitik tolak dari hal tersebut sudah banyak program peningkatan pendapatan petani peternak mengacu pada program integrasi tanaman dan ternak dengan melibatkan ternak (Kusnadi, 2007; Hamdani, 2008: Kariyasa 2005).

Dengan adanya sistem pertanian terpadu petani semakin sejahtera karena telah ada peningkatan pendapatan. Jika harga sayur turun petani masih punya penghasilan lain yaitu dari ternak sapi, yang setiap tahun dapat menghasilkan anak dan pupuk. Petani yang memiliki sapi menjadikan kotoran sapi untuk biogas sehingga tidak perlu membeli gas untuk memasak.

Jagung di perlukan untuk produk olahan jagung dan pakan ternak, tanaman jangung juga akan menghasilkan limbah jagung baik jerami, tongkol. Jumlah produk ikutan tanaman jagung dapat diperoleh dari satuan luas tanaman jagung berkisar $2,5-3,4$ ton bahan kering per Ha. Jumlah tersebut mampu menyediakan bahan baku pakan sumber serat/penganti hijauan untuk sejumlah $1 \mathrm{ST}$ 
(bobot hidup setara $250 \mathrm{~kg}$,komsumsi bahan kering $3 \%$ bobot hidup) dalam setahun

\section{Model Pertanian Terpadu}

Model Pertanian terpadu ternak sapi maksimal di pelihara 21 ekor dan hortikultura 4,22 ha. Pendapatan maksimal dari pertanian terpadu hortikultura dan ternak Rp 3.96142,5 perbulan.

\section{KESIMPULAN}

1. Pertanian terpadu ternak sapi maksimal di pelihara 21 ekor, hortikultura 4,22 ha. Pendapatan maksimal dari pertanian terpadu hortikultura dan ternak $\mathrm{Rp}$ $3.96142,5$ perbulan

2. Pertanian terpadu tanaman hortikultura dan ternak sapi dapat meningkatkan pendapatan petani serta dapat memanfaatkan lahan kosong menjadi produktif.

3. Bentuk usahatani terpadu; (a).Tanaman sayuran dan ternak sapi; bayam, kangkung, sawi, slada. (b). Tanaman buah - buahan dan ternak sapi; papaya, melon, nangka, sawo.

4. Rata - luas lahan garapan 0,3 ha, pemilikan ternak sapi 4- 5 ekor .

5. Pola usahatani terpadu mampu meningkatkan pendapatan petani dari hortilkultura perperiode tanam $\mathrm{Rp}$ 9.731.147,- dari usaha ternak $\mathrm{Rp}$ 9.345.328,-per tahun.

\section{UCAPAN TERIMAKASIH}

Peneliti mengucapkan terimakasih kepada DP2M DIKTI yang telah memberi dana penelitian Hibah Bersaing system Disentralisasi pada KOPERTIS Wilayah $\mathrm{X}$ Sumbar, Riau, Jambi dan Kepulauan Riau. Juga kepada KOPERTIS Wilayah $\mathrm{X}$ yang telah menfasilitasi penelitian ini.

\section{DAFTAR PUSTAKA}

Asmon, D. 2004. Analisis Ekonomi Usahatani Sayuran di Pekanbaru. Institut Pertanian Bogor.
Cooley, R. H. U. 2003. Oil Palam; A Mayor Tropica Crop.

Bunasor, 1990. Diversifikasi dan Program Pembangunan Pertanian. Pustaka Sinar Harapan .Jakarta.

Ginting, G. S. 1991. Keterpaduan Ternak Ruminansia dengan Perkebunan.1. Produksi dan Nilai Nutrisi. Jurnal Penelitian dan Pengembangan Pertanian. Badan Penelitian dan Pengembangan Pertanian.Departemen Pertanian.

Hamdani, 2008. Sistem Pertanian Terpadu untuk Peningkatan Produktivitas Lahan dan Kesejahteraan Petani. Makalah Workshop Teknologi untuk Masyarakat. Gedung KORPRI. Serang- Banten. 24 Desember 2008.

Hutabarat, T. S. P. N. 2002. Pendekatan Kawasan dalam Pembangunan Peternakan. Direktorat Jenderal Bina Produksi Peternakan, Departemen Pertanian. Jakarta. 1-13

Kariyasa ,K.2005. Sistem Integrasi Tanaman Ternak dalam Perspektif Reorientasi Kebijakan Subsidi Pupuk dan Peningkatan Pendapatan petani .Analisis Kebijakan Pangan. Vol.3 No.1. Maret 2005. Pusat Penelitian dan Pengembangan Sosial Ekonomi Pertanian. Badan Litbang Pertanian. Jakarta.

Kusnadi, U. 2007. Inovasi Teknologi Peternakan dalam Sistem Integrasi Tanaman dan Ternak (SITT)Untuk Menunjang Swasembada Daging Tahun 2010. Orasi pengukuhan Professor riset Badan Penelitian dan Pengembangan Pertanian.

Nizar ,R. Niken N. 2011. Analisis Pendapatan dan Optimalisasi Pola Tanam Usahatani Sayuran di Kelurahan Sidomulyo Barat Kecamatan Tampan kota Pekanbaru. 